Željko Jovanović1, Dejan Petrović ${ }^{2}$

${ }^{1}$ Actavis Ltd., Belgrade, Serbia

${ }^{2}$ University of Belgrade, Faculty of Organizational Sciences, Serbia

\title{
Implications of Redesigning the Global Pharmaceutical Industry on the Serbian Market
}

\author{
UDC: 339.13:661.12(497.11)
}

005.591:005.21

DOI: 10.7595/management.fon.2015.0001

\begin{abstract}
Business activities of pharmaceutical companies, especially in the last three decades, present numerous challenges. In the times of market changes, strengthening of competitors, development of new products, intensified statutory regulations, for a modern pharmaceutical company to retain its place in the market, it is necessary that it should change continually and adapt to new business conditions. This paper presents an analysis of the pharmaceutical industry and its position in the contemporary economic flows. The basic intention of the author is to point out the importance of the pharmaceutical industry in particularly turbulent times, as well as to closely acquaint all interested parties, especially the general and professional public, with events within the industry. The main objectives of the paper are to analyze: the current situation in the pharmaceutical industry globally; basic challenges encountered by the industry; its perspectives for the future; to identify and analyze business activities of the pharmaceutical companies in the Serbian market, and to identify the initiators of its future development considering external factors that influence it, especially the state policy in the healthcare sector, as well as economic problems featured in all developing countries.
\end{abstract}

Keywords: pharmaceutical industry, innovative and generic companies, transformation, therapeutic substitution

\section{Introduction}

The pharmaceutical sector today, more than ever before, is in the state of dynamic changes. It is a global trend, full of uncertainty and fantastic turbulence, often impaired by wrong judgement and applied strategies. The new millennium brings new temptations and challenges to the social, political and economic sectors. From traditional medication production to the modern pharmaceutical industry, an enormously long road has been crossed. This road is characterized by major changes during the twentieth century, such as formation and rise of the big pharmaceutical companies in the fifties, thalidomide disaster in the sixties, new management strategies in the seventies, global integration and concentration of capital in the nineties and at the beginning of the XXI century. Dynamic factors in the last three decades are pushing the pharmaceutical sector strongly forward, not allowing for stagnation or lethargy. Its leading representatives are today concentrated in only few globally acknowledged corporations. At the same time, strong competition in this area imposes the need for constant innovation and launching new, high quality products in the market. Also, new information technologies based on the Internet, as well as formation of new scientific fields, have opened a new space for revolutionary changes in this sector.

\section{The pharmaceutical industry today}

The basic feature of the global pharmaceutical industry in the last twenty years is a highly pronounced level of concentration. The global pharmaceutical market is currently dominated by fifteen largest innovative pharmaceutical companies. Their income overcomes tens of billions US dollars, while profits in most cases amount to several billion US dollars. Table 1 shows the basic profitability indicators of the largest pharmaceutical companies in 2013. 
Table 1. The largest global pharmaceutical companies, profitability indicators, 2013, billion USD

\begin{tabular}{|l|l|l|l|l|l|}
\hline & Income & GM & EBITDA & GM\% & EBITDA\% \\
\hline $\mathrm{J} \& \mathrm{~J}$ & 71.31 & 45.57 & 22.96 & $63.90 \%$ & $32.20 \%$ \\
\hline Novartis & 58.48 & 38.80 & 17.19 & $66.35 \%$ & $29.39 \%$ \\
\hline Pfizer & 56.25 & 47.65 & 24.62 & $84.71 \%$ & $43.77 \%$ \\
\hline Roche & 51.85 & 35.51 & 19.79 & $68.49 \%$ & $38.17 \%$ \\
\hline Merck & 44.45 & 30.82 & 15.36 & $69.34 \%$ & $34.56 \%$ \\
\hline Sanofi & 43.27 & 32.75 & 13.40 & $75.69 \%$ & $30.97 \%$ \\
\hline GSK & 42.44 & 31.17 & 14.92 & $73.44 \%$ & $35.16 \%$ \\
\hline Abbott & 42.44 & 31.17 & 14.92 & $73.44 \%$ & $35.16 \%$ \\
\hline Bayer & 40.15 & 20.70 & 8.97 & $35.16 \%$ & $22.34 \%$ \\
\hline AstraZeneca & 26.15 & 22.58 & 9.90 & $22.34 \%$ & $37.86 \%$ \\
\hline Eli Lilly & 23.26 & 17.81 & 7.26 & $76.57 \%$ & $31.21 \%$ \\
\hline BMS & 23.26 & 17.81 & 7.26 & $76.57 \%$ & $31.21 \%$ \\
\hline
\end{tabular}

Sources: www.finance.yahoo.com, www.nyse.com, official company sites, internal sources

It is important to point out that the basis of these companies' income consists of medication production and sales, which is to say that only in few cases is the listed companies' income generated by production and sales of other products. In the majority of these companies the income generated by pharmaceuticals amounts to over $70 \%$ of their total income. Supporting activities of these companies are mostly connected to the healthcare sector and primarily include production and sales of the OTC products, medical remedies, medical equipment, veterinary and cosmetic products, and the like.

The companies that generate income lower than $50 \%$ from medication production and that rank in the group of the biggest global pharmaceutical companies are Johnson \& Johnson and Bayer, while the companies Eli Lilly and AstraZeneca are examples of companies which generate $100 \%$ of their income through medication production and sales, which leads to a conclusion that pharmaceutical companies are not diversified.

Revenues of pharmaceutical companies are expressed by tens of billions USD, while profit rates are in most cases over $30 \%$. It is important to note that production costs vary between $20 \%$ and $35 \%$, while operation costs amount to around $30 \%$ of the companies' total income. Novartis achieved the greatest revenue from the sales of the pharmaceutical products in 2013.

In the last twenty years big pharmaceutical companies have gone through a phase of significant transformations. Large income, high profitability and liquidity are the basic prerequisites for their growth and development. In the pharmaceutical industry the size of a company does not guarantee business success, but one should not ignore the fact that big companies take advantage through the economies of scale and opportunities to invest in research and development (R\&D), which could provide new molecules and a steady source of income for them in the future. The M\&A activities of the largest pharmaceutical companies, new forms of collaboration with CRO (Contract Research Organisations), divestment of auxiliary, less profitable operations all speak in favor of the need to provide new molecules.

An even more pronounced concentration of capital at all levels of the value chain may be expected in the future. Even now, big innovative companies are buying generic ones, we witness an interconnection of generic companies, and small companies that base their business on research and development are often the subject of takeover by larger companies. What can be expected in the near future is a certain form of cooperation between companies which are in business of producing pharmaceuticals and those that distribute them, and even a takeover of retailers by companies that trade in medications on a large scale. 


\section{Transformation of the pharmaceutical industry}

One of the most frequent strategic destinations of big pharmaceutical companies is taking over other, smaller pharmaceutical companies with a potential to provide medications for new therapeutic groups, but also for new markets. The M\&A activities are today the most frequent form of strategic changes in the contemporary pharmaceutical industry.

One of significant examples of the M\&A is the takeover of Wyeth by Pfizer in January 2009. The value of this transaction was 68 billion US dollars, and the Wyeth takeover will enable the new owners to enlarge their business activities in the areas of vaccines, OTC and veterinary products. This move was, among other things, a result of the expected crisis in 2011 , the cause of which was the patent expiry of one of the best selling medications in the history of pharmacy, Liptor. On the basis of this, the company lost around USD 12 billion during that year alone (Leonie, Ed, \& Max, 2014). By 2013,38\% of this company's products will be facing competition from generic companies, which will have particularly negative implications for the company's business in general. The Wyeth companies have in their portfolio at least 15 products which are sold in values of over 1 billion USD yearly. The takeover of this company grants Pfizer lesser dependance on a small number of Blockbusters with the monopoly status.

Takeovers and acquisitions are not a novelty in the pharmacy sector. Pfizer took over Warner-Lambert in 2000 , as well as Pharmacia in 2003. It is important to note that a reduction in number of employes occurred after these acquisitions. According to the public information in the official company documents, headcount was reduced by 20 thousand, while costs reduction amounted to around 4 billion USD.

A growing number of innovative companies are facing and will face such and/or similar challenges. The example of Wyeth testifies to this ascertainment. The pharmaceuticals Effexor for depression treatment and Protonix, the proton pump inhibitor, came to the term of patent in 2010 and 2011, respectively.

Also, the Swiss company Roche became the owner of the biotechnological company Genentech in March 2009. The value of this transaction was 46.8 billion USD. These two companies had been collaborating since the 1980s and even back then there were assumptions that at a certain moment the two companies would merge. Today Roche owns around $60 \%$ of the Genetech shares.

Between 2007 and 2012 innovative companies lost around 115 billion US dollars on the grounds of the term of patent. Challenges in the R\&D area, patent rights expiry, pressure from generic companies are but a few reasons speaking in favour of necessary implementation of continuous strategic changes in the pharmacy sector, since that is the only way for companies to ensure successful business in such a turbulent market, and it is considered that the basis for strategic changes should be the M\&A activities (Calo-Fernandez \&Martýnez Hurtado, 2012).

The fixed model of large innovative companies which means vast global income from few molecules, that has become Blockbusters due to enormous investment in promotion and marketing, is becoming ever less sustainable. One of the options is the strategy used in the Pfizer Wyeth case, a company takeover, followed by the market and portfolio takeover, as well as radical reduction in headcount. But this is only a short-term measure to save an already significantly lost income and create costs reduction until a new Blockbuster emerges. Taking over companies to this degree can be questionable, since in a number of cases it has been proved that mergers did not create synergy; on the contrary, the added value was not created, and losses based in the term of patent, especially for pharmaceuticals such as Liptor, are very hard to compensate for. In a large number of cases such strategic decisions have proven to be merely buying time.

It is important to note that at this moment innovations are not in focus as they should be, and the M\&A activities are very often a result of the present crisis. If there is a deficit in innovations, the M\&A may be considered as corrective measures in companies' operations. 


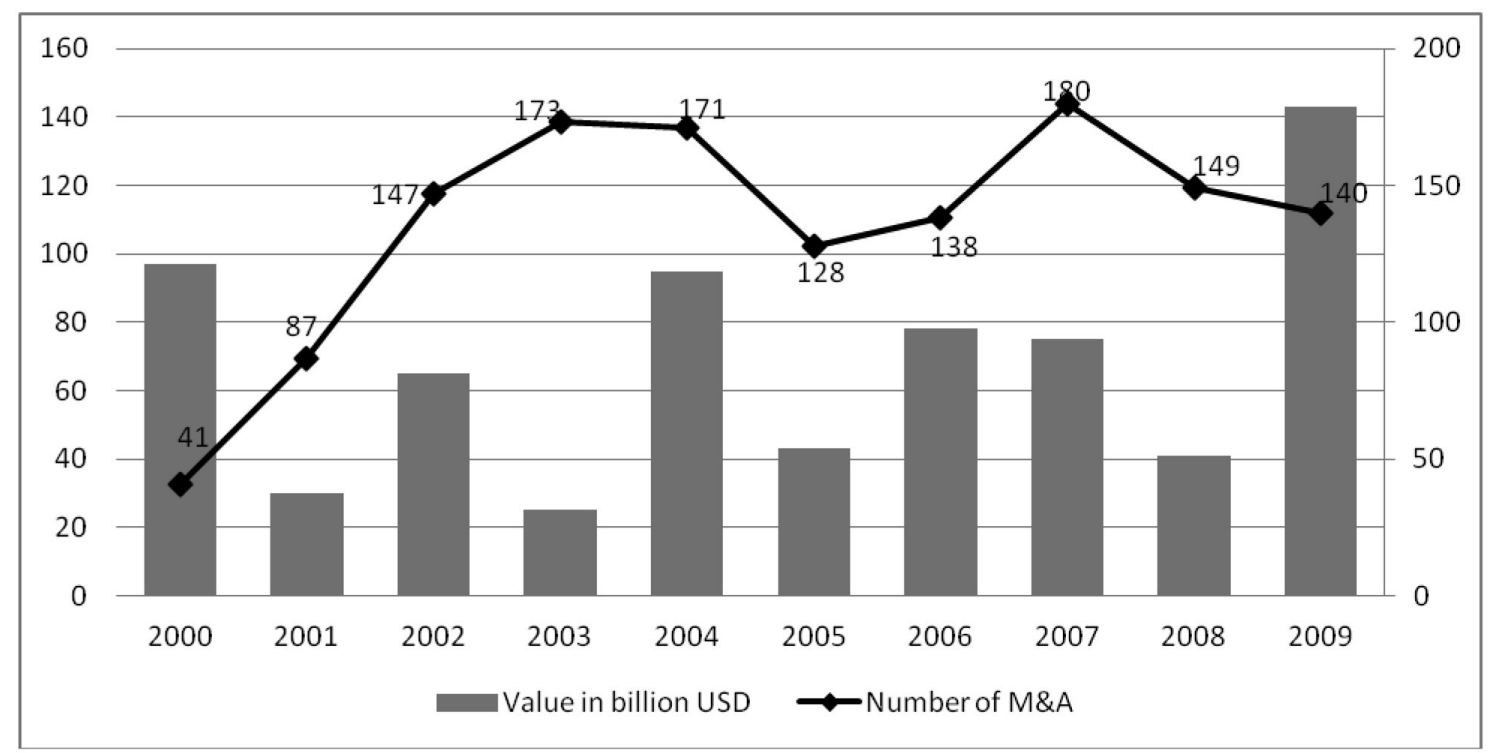

Graph 1. The value and number of the M\&A between 2000-2009 in the pharmaceutical industry globally

The data shown in Graph 1 (Pharma 2020: The vision Which path will you take? 2010) shows an enormous number and value of mergers and acquisitions in the pharmaceutical industry in the first decade of the XXI century. The total number of mergers and acquisitions was 1354 , and the total value of transactions was over USD 690 billion.

In a certain number of cases such type of changes in the industry which for the most part has a strategic character has not significantly contributed to solving companies' fundamental problems, and especially, it has not increased productivity in the R\&D area. However, it cannot be denied that such changes have created a new value for shareholders and enabled business sustainability for companies facing problems of the term of patent and production portfolio sustainability. The conclusion to be drawn is that "megamergers" have played a key role in the creation of the global pharmaceutical industry in the last 15 years. Megamergers can be defined as operations of merging/taking over companies the value of which is over 10 billion USD, where the target company has at least $10 \%$ of participation in sales and $20 \%$ of market capitalization of the acquirer. The fact is that the largest pharmaceutical companies have had such a type of business activities since 2005 to this day and that these activities, according to the Mc Kinsey results, have had a positive impact upon those companies' business performance (revenue increase, margin growth, launching new products (NPIs) and portfolio improvement) due to mergers (Cha \& Lorriman, 2014).

Regardless of the current situation in the global pharmaceutical market, it is to be expected that those companies should continue to grow in the following period. The basic reasons that lead to such a conclusion are, above all, of social and demographic character. That is to say that changes in population numbers, their age structure and lifestyles will significantly influence an increasing demand for pharmaceutical products. Also, the significant development of science and technology, growth of life standard globally, as well as the ever faster flow of information, should not be left out.

Big pharmaceutical corporations are focused on the markets in developed countries; however, the potential of developing countries, especially China, India, the Central and Eastern Europe and the Latin America countries should not be neglected. The population of these countries enjoys significantly lower level of adequate health protection, which represents a great chance for the development of pharmaceutical sector in general.

The future of the pharmaceutical industry is development of new molecules. This is the reason why big pharmaceutical companies are investing billions of USD in these activities. Also, the patent protection grants companies exclusive sales rights, which grants their revenue for the following period. Of course, the time 
needed to develop and place a new molecule in the market should not be forgotten. In a number of cases it takes several years, sometimes even decades, to develop a new molecule. Very often, a vast number of molecules, sometimes counted by thousands, is never launched in the market for various reasons, and it often happens that certain medications are developed by coincidence, but produce revolutionary results. Such is the example of the molecule Sildenafil (Viagra), which was supposed to be a pharmaceutical for cardiovascular conditions.

\section{Challenges facing pharmaceutical companies}

It should not be forgotten that pharmaceutical companies face serious challenges in four different areas of their business activities. Pressure from competitors has been extraordinary in the last twenty years, especially from the large generic companies, which are more than ever becoming serious participants in the pharmaceutical market. Secondly, companies are faced with the prices control issues. Namely, the health funds are trying to influence the altitude of these products in various ways. This phenomenon is expressed in all markets, especially those belonging to developing countries. The basic problems are limited state budgets for financing healthcare on one side, and the requisite for adequate therapy to cover the needs of the population, on the other. The third important problem the companies are faced with is the term of patent. After a certain time generic companies may produce medications that were once subject to patent restrictions, which represents a serious blow for the income of innovative companies; this is also linked with the problem of investment in research, development and creation of new molecules, as the basic initiator and generator of these companies' revenues.

Pressure from competitors as one of the basic challenges facing pharmaceutical companies may be considered from two standpoints. In the first case there is competition between innovative companies themselves. The biggest companies are investing tremendously in research and development and very often their fields of research are the same. The biggest potential is surely contained in the areas of cardiovascular, oncological, psychiatric and gastroenterological conditions.

Secondly, pressure from generic companies is growing stronger. Namely, expenditures in research and development of these companies are negligibly small and after the term of patent, those companies are launching products at dramatically lower prices in comparison with the prices originating from innovative companies. This influences a dramatic decrease of market participation revenues of innovative companies. After the term of patent, the large pharmaceutical companies "Big Pharma" lost exclusivity in production of the most profitable molecules, which has resulted in profits transfer to generic companies and decrease in market price of the medicine. From the state funds standpoint, the term of patent can be considered a very good news because it enables treatment of a greater number of patients, as well as investment in purchase of new, modern innovative pharmaceuticals.

The pharmaceutical industry is characterized by exceptionally restrictive legal regulations, which is to say that it performs its activities in a highly regulated environment. One of the reasons is the very character of pharmaceutical products, and another, very important reason lies in the fact that the biggest buyer of pharmaceutical products is the state. The level of regulation, or dependance of the industry on the state, is diverse in different markets. In highly developed countries the legal frame for companies' business is wider, which is a direct consequence of the greater purchasing power of the population. In developing countries the situation is totally different. The degree of state involvement in business of the pharmaceutical sector is greater, the public market for the pharmaceutical products is larger; therefore, the power of the state to influence the business of companies is more pronounced. One of the forms of direct state influence on companies' business is the pricing policy and its regulation. The relationship between the state and pharmaceutical companies is unbreakable, but in any case, it should be pointed out that their interests may be interpreted as diametrically opposed. On one side the basic interest of the pharmaceutical companies is profit, and on the other side the basic state interest is a continuous supply of high quality and cheap medications. In the USA the private medications market is not controlled, while in Japan and the European countries the state strictly controls prices of pharmaceuticals through various mechanisms, which results in significantly divergent prices of medications in certain markets. One of the frequent models is the reference price model, which determines a maximum price of a medication. 
Also, it should not be forgotten that various markets have their specific features, which influences operations of all pharmaceutical companies in the market to a large extent. Markets can be divided into Branded and Tender, where specificity of each market means fundamentally diverse business strategies of the participating companies. Currently Serbia is a Branded (Generics) market, but with a tendency towards transformation into the Tender category market.

Generic pharmaceutical companies represent a serious threat to innovative companies. After the term of patent, sometimes even earlier, generic companies launch products at a much lower price than the innovative ones. As a result, innovative companies face a significant decrease in income from sales of the listed products. Such examples are numerous, and losses amount to billions of USD. For all those reasons, the patent protection is an exceptionally important issue with direct influence on the development of the pharmaceutical industry in general.

The future of the pharmaceutical industry depends on contriving new molecules and launching new products. In that sense, the portfolio management is one of the key success factors for pharmaceutical companies. Research and development of molecules sometimes takes a few years; an exceptionally small number of new molecules reach the production phase, and the price of developing one molecule is around one billion USD. For those reasons innovative companies have exclusive sales rights for molecules, for a certain period. After the expiration of this period, the revenue generated from sales of those products decreases dramatically, so it is of utmost importance that a company develops a new molecule by the time the patent protection has expired. One of the ways to manage portfolio are the M\&A of smaller R\&D companies, which can provide stability of income to a certain extent, but also decrease company profitability in a short term.

\section{Possibility for international expansion}

The headquarters of the biggest global pharmaceutical companies is the USA; a smaller number originates from Western Europe, while the companies from China and India are mostly generic and relatively modestly represented in the global market. The fact that the USA and Western Europe are the largest pharmaceutical markets also corroborates the above statement. According to the IMS data, the market for pharmaceutical products in the USA comprises around 50\% of the global market and amounts to around USD 270 billion, while one third of the total global market belongs to Europe, which is around USD 170 billion. However, it is important to point out that in the last twenty years there has been a sudden development of the markets in developing countries, especially in Latin America, China and India, as shown by the yearly growth rates of these markets. Among the reasons for growth of these markets are: economic and industrial growth of the countries, development of the healthcare sector, changes in health culture, and the like.

Table 2. The global pharmaceutical market, 2005-2012, billion USD

\begin{tabular}{|l|r|r|r|r|r|r|r|r|}
\hline & 2005 & 2006 & 2007 & 2008 & 2009 & $\mathbf{2 0 1 0}$ & $\mathbf{2 0 1 1}$ & 2012 \\
\hline Market, billion USD & 645.5 & 691.0 & 739.5 & 786.7 & 842.6 & 889.4 & 936.9 & 959.0 \\
\hline Growth, YOY, \% & $7.40 \%$ & $7.00 \%$ & $7.00 \%$ & $7.00 \%$ & $7.10 \%$ & $5.60 \%$ & $5.60 \%$ & $2.40 \%$ \\
\hline
\end{tabular}

Source: www.imshealth.com 


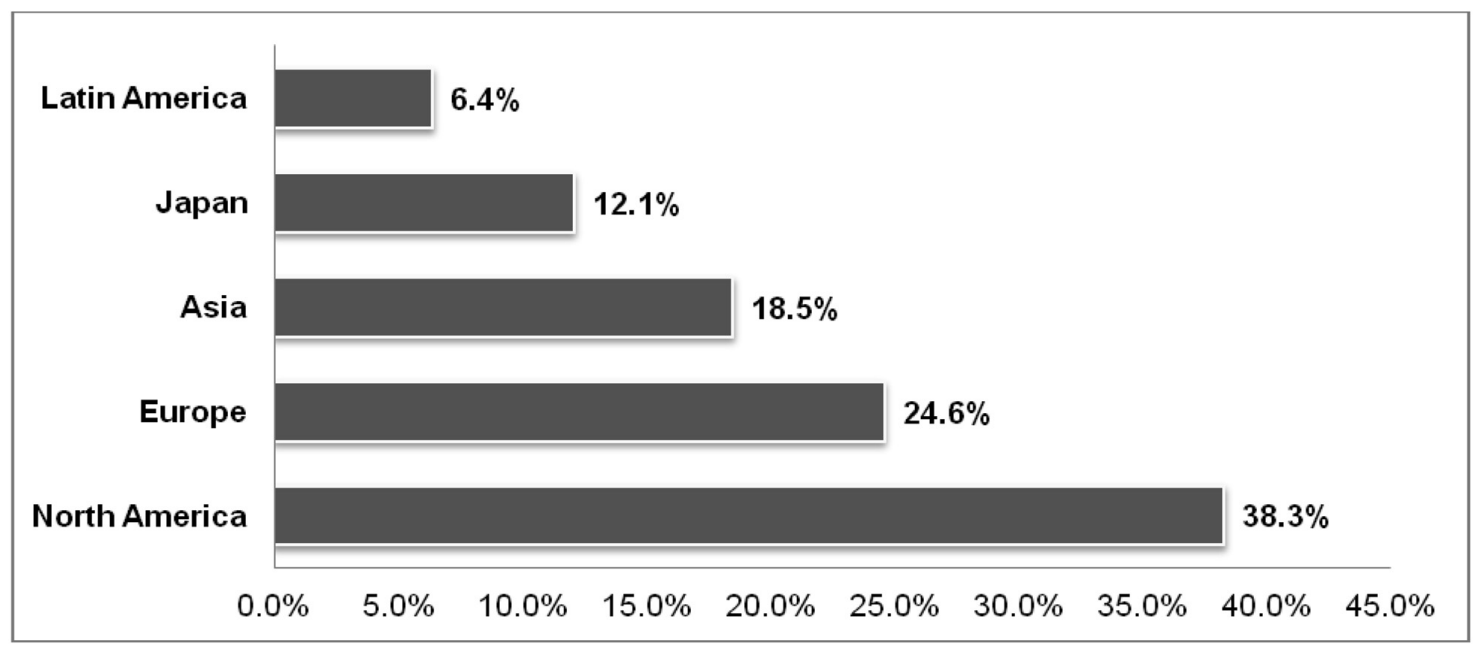

Illustration 1. The global pharmaceutical market, 2012 by regions, \% Source: Stirling, C. (2011). Future Pharma: Five Strategies to Accelerate the Transformation of the Pharmaceutical Industry by 2020. KPMG LLP.

It is realistic to expect that the pharmaceutical industry will continue to develop and grow, and that changes will be quicker and more intensive. Structural changes should affect their further growth and profitability, and one of the main points of focus in the following period will be directed at research and development, relative to development of new molecules. Also, changes in the surroundings that significantly influence the direction and dynamics of the industry development should be considered.

Table 3. The global pharmaceutical market by regions, YoY\%

\begin{tabular}{|l|r|r|r|r|r|}
\hline & 2011 & 2012 & 2013 Fc & $\begin{array}{c}\text { 2007-2012 } \\
\text { CAGR }\end{array}$ & $\begin{array}{c}\text { 2013-2017 } \\
\text { CAGR }\end{array}$ \\
\hline North America & 3.4 & -1.0 & -3.0 & 3.0 & $0.7-3.7$ \\
\hline Europe & 0.9 & -0.8 & -3.0 & 2.4 & -3.0 \\
\hline Asia & 12.8 & 12.8 & $11.4-14.4$ & 15.0 & $11.4-14.4$ \\
\hline Japan & 5.6 & 0.0 & $2.8-5.8$ & 3.0 & $1.7-4.7$ \\
\hline Latin America & 12.4 & 10.0 & $9.0-12.0$ & 12.0 & $10 .-13.0$ \\
\hline
\end{tabular}

Source: www.imshealth.com

\section{Perspectives of the pharmaceutical industry in Serbia}

It is a fact that Serbia is one of the least developed European countries, facing serious political and economic problems in the last two decades. Transformation of the pharmaceutical sector in Serbia, as one of the most important industries, is closely connected to the transformation of complete political and economic environment. Changes in this area must follow changes in the state policy toward healthcare in general, since the system sustainability in all its elements is very questionable in this period.

The pharmaceutical companies in Serbia must be aware of the necessity of change, as well as of the connection between those changes and the ones affecting the complete economic and political system. Changes at the state level should represent the basis and a necessary precondition for changes at company levels. The pharmaceutical industry, as well as the entire healthcare system, are in the process of transition. The speed of adjustment to the new business conditions, which implies ever tougher market competition, technical-technological development, new trends in developing medical products, is of fundamental 
importance for further development of the pharmaceutical industry in Serbia. The fact is that due to all circumstances the pharmaceutical industry needs a shift where the role of the state and readiness of companies for change are of the utmost importance for this industry branch.

Considering all relevant elements, it can be concluded that development and changes of the pharmaceutical companies in Serbia will be determined by the dynamics of development of the entire healthcare system in the country, since the pharmaceutical industry in any country, and especially in a country in transition such as Serbia, is a voluminous state job.

Efficiency increase in the healthcare system of Serbia will basically depend on the ability of generic pharmaceutical companies to deliver high quality and cheap generic medications to the market. Considering the disadvantageous situation in the economy, very limited financial means of the state, low purchasing power of the population and a growing demand for treatment of an increasing number of patients, the basic request to be fulfilled is that all participants in this system should have benefits, which means a steady delivery of high quality medications for the state, an acceptable level of profitability for the pharmaceutical companies, and the most important is that the user, or patient, receives an adequate therapy (win-win principle).

More than 30 pharmaceutical companies perform their business activities in Serbia, among them big local generic producers, Galenika (a state owned company), Hemofarm (a company dependent on the global generic producer Stada) and Zdravlje (a company dependent on the global generic producer Actavis).

Therefore, the focus of the state should be to provide support to generic pharmaceutical companies, because at this moment they are capable of fulfilling the above listed requirements.

By depriving generic producers of support, Serbia might face the following risks:

1. irregular supply as a consequence of innovative companies' lack of flexibility;

2. growing medication prices and state costs;

3. the future of the local generic producers and potential social problems generated thereof;

4. negative implications for macroeconomic indicators (GDP, trade balance and employment).

Generic pharmaceutical companies that, of course, comply with the global production standards (GMP) must be the basic element of stability for the pharmaceutical sector in the country. Production of a high volume of cheap and high quality medications (according to the principle: High Volume, Low price, High Quality) may satisfy the need of the country for these strategic products.

One of the opportunities for the industry in Serbia is to launch medications prior to the EU or neighbouring countries. Namely, the local legislation enables earlier launching of new molecules due to a shorter period for the term of patent than in the EU countries, which opens up the opportunity to supply markets with new therapies at lower prices. One such example is launching the generic Imatinib, which enabled the state to save more than one million euros.

An early entry of a generic medication in the Serbian market leads to savings, and in such a way local generic producers offer approach to modern therapies to the healthcare system of Serbia at lower prices in comparison with those offered by foreign innovative companies.

Also, it should not be forgotten that there are trade agreements, in particular with the Russian Federation, as well as with the former USSR countries, potentially enabling the expansion of these products' export, which could of course have a positive effect on medication prices in the local market too. Namely, increased usage of the existing and underused capacities directly influences prices, and consequently competitiveness of the listed products, which ultimately decreases the possibility of medication shortages in the local market; that is, provides regular market supply along with significant savings for the state.

According to the data shown in Table 4, the size of the pharmaceutical market is around USD 900 million (including the OTC products the value of which is around $10 \%$ of the total pharmaceutical market), which represents around $2 \%$ GDP, or around $20 \%$ of healthcare yearly costs, while medication sales per capita amounts to USD 120-140. It is important to point out that significant growth of around $4 \%$ has been projected until 2016; however, the current circumstances affecting the country may influence the listed indicators 
negatively. Here we primarily relate to the continuous and all the more intense political instability, on one hand, and less than stable and predictable economic parameters, on the other.

According to the data shown in Table 5 and Table 6, participation of the innovative medications in total consumption was around $30 \%$, while generic medications make up to $70 \%$ of the market and, according to estimations, that trend is not about to change significantly in the next few years.

Changing this relation implies a shift in the state policy toward the healthcare sector, which at this moment may be an uneasy solution, but also the only genuine one.

Table 4. Pharmaceutical sales in Serbia, in total, 2008-2016, basic indicators

\begin{tabular}{|l|r|r|r|r|r|r|r|}
\hline & $\mathbf{2 0 1 0}$ & $\mathbf{2 0 1 1}$ & $\mathbf{2 0 1 2}$ & $\mathbf{2 0 1 3}$ & $\mathbf{2 0 1 4}$ & $\mathbf{2 0 1 5}$ & $\mathbf{2 0 1 6}$ \\
\hline Sales, billUSD & 0.862 & 1.020 & 0.865 & 0.872 & 0.907 & 0.948 & 0.989 \\
\hline Sales, billUSD, \% y-o-y & -18.1 & 18.3 & -15.2 & 0.8 & 4.0 & 4.5 & 4.3 \\
\hline Sales, billRSD & 67.071 & 74.784 & 78.246 & 81.493 & 86.936 & 92.836 & 99.308 \\
\hline Sales, billRSD, \% y-o-y & -5.8 & 11.5 & 4.6 & 4.1 & 6.7 & 6.8 & 7.0 \\
\hline Sales per capita, USD & 140.2 & 119.3 & 120.6 & 125.8 & 131.9 & 137.9 & 143.8 \\
\hline Sales, \% GDP & 2.31 & 2.27 & 2.20 & 2.16 & 2.10 & 2.07 & 2.1 \\
\hline Sales, \% of healthcare costs & 22.30 & 21.89 & 21.23 & 20.93 & 20.62 & 20.43 & 2.3 \\
\hline
\end{tabular}

Source: Emerging Europe Monitor SEE. BMI, March 2013

Table 5. Sales of innovative medications in Serbia, 2008-2016, basic indicators

\begin{tabular}{|l|r|r|r|r|r|r|r|}
\hline & $\mathbf{2 0 1 0}$ & $\mathbf{2 0 1 1}$ & $\mathbf{2 0 1 2}$ & $\mathbf{2 0 1 3}$ & $\mathbf{2 0 1 4}$ & $\mathbf{2 0 1 5}$ & $\mathbf{2 0 1 6}$ \\
\hline Sales, billUSD & 0.241 & 0.285 & 0.242 & 0.243 & 0.252 & 0.262 & 0.273 \\
\hline Sales, billUSD, \% y-o-y & -19.7 & 18.3 & -15.1 & 0.4 & 3.7 & 4.0 & 4.2 \\
\hline Sales, billRSD & 18.787 & 20.922 & 21.851 & 22.703 & 24.150 & 25.702 & 27.397 \\
\hline Sales, billRSD, \% y-o-y & -7.4 & 11.4 & 4.4 & 3.9 & 6.4 & 6.4 & 6.6 \\
\hline $\begin{array}{l}\text { Sales,\% of sales of } \\
\text { prescriptionmedications }\end{array}$ & 31.5 & 31.4 & 31.3 & 31.1 & 31.0 & 30.8 & 30.7 \\
\hline Sales, \% of total sales & 28.0 & 27.9 & 28.0 & 27.9 & 27.8 & 27.6 & 27.6 \\
\hline
\end{tabular}

Source: Emerging Europe Monitor SEE. BMI, March 2013

Table 6. Sales of generic medications in Serbia, 2008-2016, basic indicators

\begin{tabular}{|l|r|r|r|r|r|r|r|}
\hline & $\mathbf{2 0 1 0}$ & $\mathbf{2 0 1 1}$ & $\mathbf{2 0 1 2}$ & $\mathbf{2 0 1 3}$ & $\mathbf{2 0 1 4}$ & $\mathbf{2 0 1 5}$ & $\mathbf{2 0 1 6}$ \\
\hline Sales, billUSD & 0.525 & 0.624 & 0.531 & 0.538 & 0.562 & 0.590 & 0.617 \\
\hline Sales, billUSD, \% y-o-y & -17.5 & 18.9 & -14.9 & 1.3 & 4.5 & 5.0 & 4.6 \\
\hline Sales, billRSD & 40.846 & 45.748 & 48.074 & 50.277 & 53.227 & 57.722 & 61.988 \\
\hline Sales, billRSD, \% y-0-y & -5.0 & 12.0 & 5.1 & 4.6 & 5.9 & 8.4 & 7.4 \\
\hline $\begin{array}{l}\text { Sales,\% of sales of prescription } \\
\text { medications }\end{array}$ & 68.5 & 68.6 & 68.7 & 68.9 & 69.0 & 69.2 & 69.3 \\
\hline Sales, \% of total sales & 60.9 & 61.2 & 61.4 & 61.7 & 62.0 & 62.2 & 62.4 \\
\hline
\end{tabular}

Source: Emerging Europe Monitor SEE. BMI, March 2013 
Stagnation, or incremental growth of the entire pharmaceutical market as the consequence of a general economic activity stagnation, inadequate and slow healthcare sector restructuring process, regulatory issues and tardiness to react to global changes in the pharmaceutical sector, general liquidity problem, problem of the prices control system which is insufficiently adequate (particularly characteristic of developing countries), production portfolio management - all point out to the necessity of reforming the healthcare sector in its totality, but also to insufficient maturity of the pharmaceutical companies in Serbia to enact changes.

Changes in the pharmaceutical industry globally are permanent; the big multinational companies are significantly present in the Serbian market; business activities of domestic production companies are not aligned with the global industry trends; problems in their business, but also insufficiently serious attitude toward the wholesale business sector, elements of unethical business, are but a few indicators pointing to the necessity of comprehensive reforms in the industry in Serbia.

\section{Conclusion}

One of the most important political problems at the moment, especially for countries in transition, is the reform of the entire healthcare system. Traditionally, the axis of the healthcare system in those countries is by nature of the public character, while in some highly developed countries, such as the USA, the main role in the healthcare system belongs to the private sector; that is, private health insurance policies and direct payments by the patients. However, it is realistic to expect that in the future greater importance will be assigned to the private segment of the healthcare sector, even in less developed countries.

A special feature of the healthcare systems in developing countries is a particularly high level of centralization. One of the directions in which this sector will be restructured will involve a larger scale decentralization, as well as removing bureaucratic obstacles in this field.

The basic problems concerning the healthcare system are primarily linked to limitations of the healthcare budget, a growing need for rationalization of total costs in this sector, as well as availability and quality of healthcare services.

Those problems in the healthcare area, especially the existing financial problems, have a direct impact on the direction and development of the pharmaceutical industry in general. As a result of the increased demand for medications and ever growing budget limitations, an even greater generification of pharmaceutical markets, even in countries characterized by almost negligable usage of generic medications, for example Italy, is to be expected.

It is extremely difficult to predict what will happen to the pharmaceutical industry in the future in global terms. Currently the most important question as regards the pharmaceutical industry globally is the measure of therapeutic substitution with generic products, which enables significant cost savings.

The leading global markets are generified in a significant measure, as exemplified by the US pharmaceutical market. The Waxman-Hetch Act allowed introduction of generic products to the US market, which has brought a dramatic reduction in healthcare costs and therefore enabled stability of the USA healthcare system. Cost savings per year, generated through introduction of generic products, amount to over USD 100 billion.

The basic features of the pharmaceutical industry in Europe in the following period will be harmonization, centralization and coordination between products registration and GMP standards; establishing a common European court to rule on issues pertaining to patent rights and their protection, and most importantly, market transformation in the direction of national INN tenders.

The future of innovative pharmaceutical companies globally is in launching new products (NMI), especially in the area of biosimilars.

Also, the pressure from the generic industry will be ever growing in the future, while state demands for costs rationalization will be even more pronounced.

Developing countries, including Serbia, will be forced to find a balance between the mentioned demands, while trying not to neglect their local specificity and problems (economic potential, life standard, the local pharmaceutical industry) and, based on these, make decisions, enabling each patient to receive adequate therapy at acceptable price at any moment. 


\section{REFERENCES}

[1] Benjamin, J. (2010). Big Pharma's Patent Cliff 2009-2013: A Comparison of Company-Level Responses and Strategic Recommendations for Pfizer, Inc. and Eli Lilly and Company.

[2] Calo-Fernandez, B., \& Martınez Hurtado, J. L. (2012). Biosimilars: Company Strategies to Capture Value from the Biologics Market. Pharmaceuticals.

[3] Cha, M., \& Lorriman, T. (2014). Why pharma megamergers work. McKinsey Insights and publications.

[4] 2011). Closing the gap? Big Pharma's growth challenge and implications for deals. Ernst \& Young Global Life Sciences Center.

[5] (2013). Emerging Europe Monitor SEE. BMI., March 2013

[6] Humer, F.(2005). Innovation in the Pharmaceutical Industry - Future Prospects. Zurich: Roche.

[7] Leonie, M., Ed, C., \& Max, V. (2014). Adopt or Die: How to survive patent cliff. Life Sciences Intellectual Property Review, Vol. 1, Issue 1.

[8] Melly, A. (2011). The 10 Biggest-Selling Medications That Are About to Lose Their Patent. Daily Finance.

[9] (2010). Pharma 2020: The vision Which path will you take? PricewaterhouseCoopers.

[10] (2010). Pharma 2020: Supplying the future Which path will you take? PWC.

[11] Philip, D. (2012). Beyond the Patent Cliff-Signs of Recovery in Biopharma's New Normal. Accenture Life Sciences.

[12] Stiglic, D. (2004). Ekonomija javnog sektora. Beograd: Ekonomski fakultet.

[13] Stirling, C. (2011). Future Pharma: Five Strategies to Accelerate the Transformation of the Pharmaceutical Industry by 2020. KPMG LLP.

[14] (2013). The Pharmaceutical Industry and Global Heath: Facts and Figures 2012. International Federation of Pharmaceutical Manufacturers and Associations.

https://nyse.nyx.com/

www.imshealth.com

www.novarts.com

www.jnj.com

www.pfizer.com

www.roche.com

www.merck.com

www.sanofi.com

www.gsk.com

www.abott.com

www.bayer.com

www.astrazeneca.com

www.lilly.com

www.bms.com 


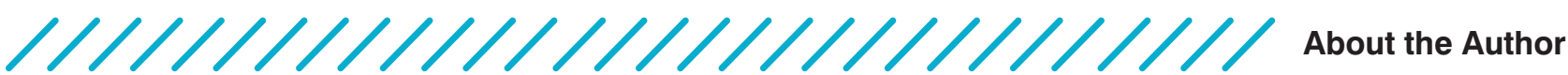

Željko Jovanović

Actavis Ltd., Belgrade, Serbia

Željko Jovanović was born in 1976. He studied at the Faculty of Economics, University of Belgrade, where he received his MSc degree. He worked with the Treasury Administration of the Ministry of Finance of the Republic of Serbia in the Public Utility Restructuring Unit, as well as with the company for trading pharmaceutical products

"Actavis Ltd", which is part of the multinational generic pharmaceutical company Actavis PLC, one of the biggest global companies for production of generic medications. He was employed in the Finance, Sales and Business Development segments.

\section{Dejan Petrović \\ University of Belgrade, Faculty of Organizational Sciences, Serbia petrovic.dejan@fon.bg.ac.rs}

Dr. Dejan Petrović is a full professor and Head of Department of Management and specialized management disciplines at the Faculty of Organizational Sciences, University of Belgrade. He is also visiting professor at several universities in the country and abroad. His research interests include management, project management, strategic management, project appraisal and change management. He has been a consultant for a wide variety of public and private organizations, and he has published books and articles in refereed journals. 